\title{
Feasibility of Obtaining Sufficient Numbers of Responses to Questions About Travel Intentions, Thereby Facilitating Effective Health Messaging
}

\author{
Neil Seeman', Danielle Goldfarb², Emily Kuzan², Mary V. Seeman ${ }^{3 *}$ \\ ${ }^{1}$ Institute of Health Policy, Management and Evaluation, University of Toronto, Toronto, Canada \\ ${ }^{2}$ RIWI Corporation, Toronto, Canada \\ ${ }^{3}$ Department of Psychiatry, University of Toronto, Toronto, Canada
}

Corresponding Author: Mary V. Seeman, MD, Professor Emerita, Department of Psychiatry, University of Toronto, Toronto, Ontario, Canada. Tel: +1-416 486 3456, Email: mary.seeman@utoronto.ca

Received March 1, 2019; Accepted April 19, 2019; Online Published May 20, 2019

\begin{abstract}
Introduction: The medical literature has identified a variety of health risks associated with travel. Risks depend on the susceptibility of the traveler, the specifics of the destination, the mode of transport, and on chance events. Ill-prepared travelers who underestimate travel risks may encounter a variety of health problems. In order to eventually increase the capability of travel risk prediction, the current study aimed to ascertain travel intent in China, a country traditionally difficult to penetrate through online survey.

Methods: This pilot survey study used a reliable, anonymous, online survey method to determine the feasibility of obtaining a sufficient response in China to enable travel risk prediction.

Results: The results are encouraging in that seven and a half thousand individuals in China responded over the course of one month. Most responders were from urban centers. Three to eleven percent of the respondents were over age 55 and planning to travel to potentially hazardous destinations.

Conclusion: The combination of older age and geographic risk increases the chance of ill health during travel. Knowing who is planning to travel, where they are from, and where, when, and how they are planning to arrive at their destination opens a corridor to effective preventive public health programming and educational initiatives.

Keywords: China, Preventive Medicine, Surveys and Questionnaires, Travel Medicine
\end{abstract}

Citation: Seeman N, Goldfarb D, Kuzan E, Seeman MV. Feasibility of obtaining sufficient numbers of responses to questions about travel intentions, thereby facilitating effective health messaging. Int J Travel Med Glob Health. 2019;7(2):48-52. doi:10.15171/ijtmgh.2019.11.

\begin{abstract}
Introduction
Because individuals who are in good health are rarely concerned about the health risks of travel, they tend not to take safety precautions, non-obligatory immunization for instance. They tend not to pack essential medications such as analgesics, antibiotics, anti-diarrheals, and insect repellant in their luggage. They neglect to take important documents on their travels, such as vaccination cards, or first aid equipment. They do not anticipate severe weather conditions and rarely seek out pre-travel advice. In a study from Brazil, ${ }^{1}$ $74 \%$ of surveyed travelers perceived their travel risk to be trivial, a belief strongly associated with undue risk taking. This association is exemplified by stories of immigrants to western countries, originally from the developing world, who periodically return to their homeland to visit friends and relatives. ${ }^{2}$ Because of childhood exposure, these travelers
\end{abstract}

believe they are immune to common sources of infection in their home countries. In fact, they are, paradoxically, more vulnerable than other travelers, because they interact closely with the local population at the destination site, much more so than business travelers or tourists, and frequently attend celebratory gatherings during which infectious agents are readily spread. In addition, by virtue of intimate links with local residents, they are more susceptible than other travelers to the possibility of sexually transmitted disease. ${ }^{3}$

The literature suggests that relatively few travelers are sufficiently informed or prepared for the health hazards of travel. According to an Australian survey of 1334 passengers at Perth International Airport, only $32 \%$ had sought destinationspecific health travel advice prior to embarkation. ${ }^{4}$ A study from Spain of travelers to the tropics found that $55 \%$ of 1206 travelers had received no travel vaccines. Only 422 (less than

Copyright $\odot 2019$ The Author(s). This is an open-access article distributed under the terms of the Creative Commons Attribution License (http:// creativecommons.org/licenses/by/4.0), which permits unrestricted use, distribution, and reproduction in any medium, provided the original work is properly cited. 
a third) had taken oral malaria prophylaxis. ${ }^{5}$

A little-known fact is that 8 out of 10 individuals sustain an incident of some kind while traveling outside their own countries. ${ }^{6}$ Out of 100000 visitors to countries in the developing world, 50000 (50\%) experience a health problem during travel. Roughly 300 are admitted to a hospital, and one of these admissions results in death. Common causes of ill health while traveling include infectious disease, altitude illness, insect stings, natural disasters, sun or water-associated illness, motion sickness, deep vein thrombosis, jet lag, and traveler-specific problems such as allergies, cardiovascular problems, vaccine-associated reactions, and accidental falls and injuries. Between 2007 and 2011, it was reported that gastrointestinal, febrile, and dermatologic diseases were responsible for three quarters of travel-related illnesses and that Asia and sub-Saharan Africa were the regions where illness was most often acquired. ${ }^{7}$ The specifics of acquired infectious illness during travel depend to a significant degree on the precise location of the exposure. ${ }^{8}$ The mode of transport also plays an important part in determining the nature and severity of health hazards. As an example, in-flight medical events are frequently encountered. In the main, they involve feelings of discomfort and faintness, but they can also include gastrointestinal, respiratory and cardiovascular symptoms. Behavioral symptoms (agitation and aggression), which can lead to significant passenger injury, are relatively commonplace on airplanes. ${ }^{9}$

New digital technology and mobile devices have been used to track travel routes and estimate potential health risks at specific destinations as well as to determine the health threats posed by specific categories of travelers. ${ }^{10}$ The use of Google $\mathrm{T}^{\mathrm{TM}}$ location data, for instance, has previously been explored for this purpose. ${ }^{11}$ The hypothesis of this study is that technology can inform public health authorities in a timely manner about the travel intentions of high-risk individuals who are planning to visit high-risk locations, thus making preventive efforts possible.

Because so many pandemics arise in China, because China is the largest outbound travel market in the world, and because Hong Kong is the most visited city in the world, ${ }^{12}$ the current travel sentiment survey was piloted in China. Chinese travelers have, reportedly, been carriers of infection in the past and, at the same time, are themselves exposed to health risks when they travel abroad. ${ }^{13}$ China is an interesting region from an international travel aspect, as large numbers of Chinese have recently entered the middle class and are, as a consequence, increasingly visiting extensive areas of the world for both business and pleasure.

\section{Methods}

The study reported herein is a pilot feasibility study to determine whether a new method of online survey technology can successfully gather travel information from would-be travelers living in China, a country that has been traditionally difficult to penetrate by Western survey instruments. RIWI is a global survey technology, messaging, and predictive analytics firm. It uses a patented algorithm whereby whenever Web users make an inadvertent data input error inside the
URL bar, instead of receiving an error message, they run the chance of being exposed to an opt-in survey that targets their specific geographic region. Since everyone makes occasional input errors, the Web users reached in this way constitute a completely random sample. The algorithms used ensure that the population of respondents is representative of Web usage in the geographic area of interest. The survey is offered without incentives and the voluntary participants remain completely anonymous, because no personal data is collected. This research technique is a well-established, big data approach that has been applied in a variety of different contexts, mainly in the domain of health, but also in business. ${ }^{14-20}$ It assures the rapid capture of large samples of broad, truly randomized opinion data. Questions can be asked in the language of the region. The method is also capable of exposing regional populations across the globe to targeted communications. With respect to travel, questions can be asked not only about timing of an intended trip destination, but also about the purpose of travel and individual risks, e.g., age, immunizations, allergies, travel methods, health conditions, and potential pregnancy. Once the information is gathered, health and risk information can be directed to the appropriate geographic region. In 2015, the value of the technique was featured in the pre-eminent science journal, Nature. ${ }^{21}$

Respondents to RIWI surveys inevitably reflect the Webusing population and tend, therefore, to be relatively welleducated and younger rather than older. RIWI respondents differ in several ways from individuals who participate in door-to-door polling or paid panels. The large majority are not habitual survey takers and, because the survey is anonymous, responses are open and truthful. One advantage of RIWI is that, unlike social media analytics, RIWI surveys cannot be blocked out by governments unless the Internet is completely shut down in the country being analyzed. This is an important issue when attempting surveys in China. ${ }^{22}$ For this pilot project, intended to ascertain the number of responses from China in a given time period, no specific sample size was projected. The survey, conducted for one month (May/ June, 2019), asked about demographics and consisted of only one travel question: "Where do you plan to travel next for vacation?"

\section{Results}

The results presented are not weighted to the general population of China, because the data is representative of the online population in China, the population most likely to travel outside of China. Over one month, 7,483 persons from China responded to the survey. Twenty-seven percent of respondents had no travel plans. Thirty-two percent intended to travel within China. Another $8 \%$ were planning to travel to another Asian country. Eleven percent were planning a trip to Europe and $18 \%$ to North America (Canada and the United States). Four percent named a country destination outside of Asia, North America, or Europe (Table 1). The +/- signs in Tables 1 and 2 refer to the percent margin of error.

With respect to potential health adversities, vulnerable travelers are those over age 55 who are planning to visit either Asian countries other than China or "other" countries, 
Table 1. Where Do You Plan to Travel Next for Vacation?

\begin{tabular}{lccc}
\hline Travel Destination & No. of Respondents & Total \% & $+/ \mathbf{\%}$ \\
\hline China & 2416 & 32 & 1.1 \\
USA & 892 & 12 & 0.7 \\
Canada & 450 & 6 & 0.5 \\
Europe & 760 & 11 & 0.7 \\
Asia (except China) & 598 & 8 & 0.6 \\
Other country & 318 & 4 & 0.5 \\
Don't plan on traveling & 2049 & 27 & 1.0 \\
Total & 7483 & & \\
\hline
\end{tabular}

the two categories that include developing countries where health risks are known to be high. Three to eleven percent of Chinese travelers over the age of 55 are, thus, according to this preliminary study, planning to visit potentially highrisk destinations (Table 2). According to the current results, younger travelers, perhaps for economic reasons, are more likely to restrict their travel plans to China.

\section{Discussion}

The large number of responses obtained in one month suggests that the method we used can garner useful information about travel and travel health risks not only for China, but, by extension, for any other geographic region. Such results allow the regionally-targeted dissemination of warnings about weather conditions, natural disasters (cyclones, earthquakes, tsunamis, typhoons, hurricanes, avalanches), epidemics, ${ }^{23-25}$ civil unrest, ${ }^{26}$ water safety, ${ }^{27}$ altitude, ${ }^{28}$ air quality, ${ }^{29}$ local drug use laws, ${ }^{30}$ mass gatherings such as large-scale religious events, ${ }^{31-33}$ sports events, ${ }^{34}$ and open air music festivals that breed outbreaks of communicable disease, accidents, violent assaults, and infrastructure breakdowns, ${ }^{35}$ and inform travelers about geographic pockets of inadequate or unsafe health service availability. Time-targeted messaging can be applied to different world regions as mass travel occurs at different times in different countries. The Chinese tend to travel in late December and early January; the Japanese travel during Golden Week (April 29-early May); the French travel during August. Regionally-aimed Internet messaging can warn against health threats, recommend immunizations and how to access them, suggest safest times to travel to particular locations, make recommendations about what to bring and what foods to avoid, and inform the intended public about methods of protection against insect-transmitted and sexually-transmitted disease..$^{36,37}$

Risks depend to a large extent on the aim of travel. Some vacationers travel specifically for sexual adventure, which carries important, generally preventable, medical risks. ${ }^{38,39}$

Travel for the purpose of engaging in seasonal sports activities poses risks of serious injury, frostbite, sunburn, dehydration, heat stroke, drowning, or waterborne infection. Water sports in unknown locales are known to be major sources of disability. With regard to water accidents, one third of near drowning victims are reported to sustain neurologic sequelae that can last for life. ${ }^{40}$

Travel for the purpose of medical tourism, which is becoming increasingly popular, can also occasion a number of unexpected negative effects. ${ }^{41}$

Mental and emotional health hazards associated with travel are as common, if not more so, than physical ones, especially when the destination is unfamiliar to the visitor. Travel to which one is unaccustomed leads to an increase in general arousal and can induce anxiety and feelings of depression and confusion. ${ }^{42}$ Phobic reactions such as fear of flying, enclosed spaces, crowds, or strangers can also be triggered by travel..$^{43}$ According to the World Health Organization, mental illness constitutes one of the three main health crises encountered in air travel; the other two are physical injury and cardiac events. ${ }^{44}$

The longer the travel, the greater the associated mental health risk appears to be. Older age and cognitive decline increase the risk. Many factors contribute, notably drug and alcohol reactions, physical discomfort, forced immobility, motion sickness, loss of sleep, dehydration, jet lag, linguistic and cultural estrangement, homesickness, and specific types of destinations. There are several named psychiatric syndromes associated with travel. One example is Stendhal syndrome, named after the 19th century French writer who, when visiting Florence for the first time, was overcome with awe that he found unsettling, a reaction to the perceived magnificence of Renaissance art. The symptoms of this syndrome are temporary dissociation and disorientation. ${ }^{45}$ The Paris syndrome affects mood. It is best characterized as a serious disenchantment that springs from the contrast between the unrealistic expectations and anticipations that precede a trip to an idealized destination and its less-than-

Table 2. Travel Plans by Age Group

\begin{tabular}{|c|c|c|c|c|c|c|c|c|c|c|c|c|}
\hline Travel Destination & $\begin{array}{l}16-24 \\
\% \\
\end{array}$ & $\begin{array}{l}+/- \\
\%\end{array}$ & $\begin{array}{l}25-34 \\
\%\end{array}$ & $\begin{array}{l}+- \\
\%\end{array}$ & $\begin{array}{l}35-44 \\
\%\end{array}$ & $\begin{array}{l}+- \\
\%\end{array}$ & $\begin{array}{l}\text { 45-54 } \\
\%\end{array}$ & $\begin{array}{l}+- \\
\%\end{array}$ & $\begin{array}{l}55-64 \\
\%\end{array}$ & $\begin{array}{l}+- \\
\%\end{array}$ & $\begin{array}{l}65+ \\
\%\end{array}$ & $\begin{array}{l}+/- \\
\%\end{array}$ \\
\hline China & 34 & 1.7 & 32 & 1.8 & 32 & 2.8 & 32 & 4.7 & 25 & 6.0 & 18 & 4.5 \\
\hline USA & 11 & 1.1 & 13 & 1.1 & 12 & 2.0 & 10 & 3.0 & 15 & 4.9 & 14 & 4.1 \\
\hline Canada & 5 & 0.8 & 6 & 0.8 & 6 & 1.5 & 8 & 2.6 & 6 & 3.4 & 9 & 3.3 \\
\hline Europe & 9 & 1.0 & 10 & 1.0 & 12 & 1.9 & 11 & 3.1 & 11 & 4.3 & 9 & 3.4 \\
\hline Other country & 4 & 0.7 & 4 & 0.7 & 4 & 1.2 & 4 & 1.9 & 7 & 3.6 & 7 & 3.0 \\
\hline No travel plan & 30 & 1.6 & 26 & 1.6 & 25 & 2.6 & 28 & 4.5 & 28 & 6.1 & 35 & 5.6 \\
\hline Total & 2982 & & 2563 & & 1074 & & 385 & & 202 & & 277 & \\
\hline
\end{tabular}


perfect reality. The Tahiti syndrome is another form of disillusionment, a reaction to over-tourism. It takes the form of irritation, sometimes rage, when individuals who have traveled to what they thought were "hidden gems," seeking solitude and a communion with nature, find themselves on crowded beaches among noisy crowds of fellow tourists. The Jerusalem syndrome is a psychotic reaction during travel. It manifests in hallucinations and delusions experienced at sacred sites that have special religious significance for the traveler. ${ }^{46}$ Whatever the destination, travel away from home can induce an oppressive longing for familiar surroundings and a yearning for important persons left behind. ${ }^{47}$

\section{Conclusion}

The rate of international travel is growing rapidly, especially visits to countries with emerging economies. Persons with a variety of pre-existing illnesses are now traveling throughout the world. This increases both physical and mental travel health hazards, many of which can be anticipated and prepared for if effective advice is received and proper precautions are taken. This study shows that it is feasible to engage respondents, even in difficult-to-access countries such as China, in responding to inquiries about travel plans, giving health promotion an inroad into regions that require targeting, and elucidating when the messaging should ideally take place. Threat warnings and protective information can then be channeled to appropriate targets, such as those catering to large contingents of travelers, e.g., airlines, cruise ships, tourist boards, and group travel facilities. Frail and vulnerable residents at sites where mass visits are expected can also be warned in advance of potential incoming infection threats. The more thorough the prior knowledge about travel plans and intentions, the more effective specific health promotion campaigns can become.

\section{Authors' Contributions}

NS, DG, and EK took part in the RIWI survey and the analysis of results. All authors collaborated in writing and editing the manuscript.

\section{Conflict of Interest Disclosures}

NS, DG, and EK are employees of RIWI Corporation, a global trend-tracking firm that owns the technology used to collect the data in this study. They have not received and will not receive any remuneration from the firm for the publication of this manuscript.

\section{Ethical Approval}

The RIWI survey method adheres to the code of ethics and practices established by the American Association of Public Opinion Research (AAPOR).

\section{Funding Support}

There was no funding support for this study.

\section{References}

1. Mesquita EC, Varela MC, Alvarenga do Brasil PEA, et al. Addressing travelers' perception of risk in pre-travel care: Reports

\section{Research Highlights}

\section{What Is Already Known?}

Individuals who are ill-prepared and vulnerable because of age or pre-existing conditions run many health risks when traveling, especially when dangers of infection or natural disaster or violence await them because of destination, duration of travel, travel purpose, or mode of transport.

\section{What This Study Adds?}

It is possible to ascertain travel plans (who, when, how, why, and where) via online surveys directed at specific regions of the globe. This facilitates targeted regional public health warnings and travel advice.

from a travel clinic in Rio de Janeiro, Brazil. Rev Soc Bras Med Trop. 2019;52:e20180514. doi:10.1590/0037-8682-0514-2018.

2. Fulford $\mathrm{M}$, Keystone JS. Health risks associated with visiting friends and relatives in developing countries. Curr Infect Dis Rep. 2005;7(1):48-53. doi:10.1007/s11908-005-0023-z.

3. Heywood AE, Zwar NA. Improving access and provision of pretravel healthcare for travellers visiting friends and relatives: a review of the evidence. J Travel Med. 2018;25(1):1-8. doi:10.1093/ jtm/tay010.

4. Thomson CA, Gibbs RA, Giele C, Firth MJ, Effler PV. Health seeking behaviours and knowledge of infectious disease risks in western Australian travellers to Southeast Asian destinations: an airport survey. Trop Med Infect Dis. 2016;1(1):3. doi:10.3390/ tropicalmed1010003.

5. Lopez-Velez R, Bayas JM. Spanish travelers to high-risk areas in the tropics: airport survey of travel health knowledge, attitudes, and practices in vaccination and malaria prevention. J Travel Med. 2007;14(5):297-305. doi:10.1111/j.1708-8305.2007.00142.x.

6. International SOS. https://www.internationalsos.com/. Accessed June 25, 2019.

7. Leder K, Torresi J, Libman MD, et al. GeoSentinel surveillance of illness in returned travelers, 2007-2011. Ann Intern Med. 2013;158(6):456-468. doi:10.7326/0003-4819-158-6-20130319000005

8. Freedman DO1, Weld LH, Kozarsky PE, et al. Spectrum of disease and relation to place of exposure among ill returned travelers. N Engl J Med. 2006;354(2):119-130. doi:10.1056/NEJMoa051331.

9. Guiu G, Monin J, Perrier E, Manen O. Epidemiology of inflight medical events. Int J Travel Med Glob Health. 2019;7(11):10-12. doi:10.15171/ijtmgh.2019.03.

10. Lai S, Farnham A, Ruktanonchai NW, Tatam AJ. Measuring mobility, disease connectivity and individual risk: a review of using mobile phone data and mHealth for travel medicine. J Travel Med. 2019;26(3):1-9. doi:10.1093/jtm/taz019.

11. Ruktanonchai NW, Ruktanonchai CW, Floyd JR, Tatem AJ. Using Google Location History data to quantify fine-scale human mobility. Int J Health Geogr. 2018;17(1):28. doi:10.1186/s12942018-0150-z.

12. Global Data. https://www.globaldata.com/store/. Accessed June 25, 2019.

13. Ma T, Heywood A, Maclntyre CR. Chinese travellers visiting friends and relatives--A review of infectious risks. Travel Med Infect Dis. 2015;13(4):285-294. doi:10.1016/j.tmaid.2015.05.004.

14. Barkemeyer R, Miklian J, Responsible business in fragile contexts: comparing perceptions from domestic and foreign firms in Myanmar. Sustainability. 2019;11(3):598. doi:10.3390/ su11030598.

15. Seeman MV, Seeman N, Cho JA. Worldwide preferences for natural remedies for 'nervousness' and common colds. J Psychiatry Brain 
Sci. 2018;3 (1):1. doi:10.20900/jpbs.20180001.

16. Seeman N, Fogler SG, Seeman MV. Mental health promotion through collection of global opinion data. J Prevent Med Care. 2016;1(1):23-36.

17. Seeman N, Ing A, Rizo C. Assessing and responding in real time to online anti-vaccine sentiment during a flu pandemic. Healthc Q. 2010;13:8-15. doi:10.12927/hcq.2010.21923.

18. Seeman N, Reilly DK, Fogler S. Suicide risk factors in U.S. college students: Perceptions differ in men and women. Suicidology Online. 2017;8(2):20-26.

19. Seeman N, Seeman B. Monitoring receptivity to online health messages by tracking daily Web traffic engagement patterns: A review of more than 13 million US Web exposures over 1,235 days. Healthc Q. 2017;20(3):47-51. doi:10.12927/hcq.2017.25288.

20. Seeman N, Tang S, Brown AD, Ing A. World survey of mental illness stigma. J Affect Disord. 2016;190:115-121. doi:10.1016/j. jad.2015.10.011.

21. Seeman N. Use data to challenge mental-health stigma. Nature. 2015:528(7582):309. doi:10.1038/528309a.

22. Kato T, Kishida N, Umeyama T, Jin Y, Tsuda K. A random extraction method with high market representation for online surveys. Int J Business Innovation Res. 2019; In Press.

23. Ebola outbreak spreads from Democratic Republic of Congo Outbreak spreads. CBC News. June 12, 2019. https://www. cbsnews.com/news/uganda-ebola-death-democratic-republic-ofcongo-outbreak-spreads/. Accessed July 17, 2019.

24. Measles. CDC website. https://wwwnc.cdc.gov/travel/notices/ watch/measles-global. Accessed July 17, 2019.

25. Nipah Virus in Kerala India. https://www.internationalsos. com/newsroom/news-releases/nipah-virus-in-kerala-indiajun-06-2019. Accessed July 17, 2019.

26. Bylander J. Civil unrest, police use of force, and the public's health. Health Aff (Millwood). 2015;34(8):1264-1268. doi:10.1377/ hlthaff.2015.0717.

27. Lu Y, Song S, Wang R, et al. Impacts of soil and water pollution on food safety and health risks in China. Environ Int. 2015;77:5-15. doi:10.1016/j.envint.2014.12.010.

28. Miele $\mathrm{CH}$, Schwartz AR, Gilman $\mathrm{RH}$, et al. Increased cardiometabolic risk and worsening hypoxemia at high altitude. High Altitude Med Biol. 2016;17(2):93-100. doi:10.1089/ ham.2015.0084.

29. Fattore E, Paiano V, Borgini A, et al. Human health risk in relation to air quality in two municipalities in an industrialized area of Northern Italy. Environ Res. 2011;111(8):1321-1327. doi:10.1016/j.envres.2011.06.012.

30. Drugs. Available at: https://travel.gc.ca/travelling/health-safety/ drugs. Accessed July 17, 2019.

31. Gautret P, Steffen R. Communicable diseases as health risks at mass gatherings other than Hajj: what is the evidence? Int J Infect Dis. 2016;47:46-52. doi:10.1016/j.ijid.2016.03.007.

32. Khan ID, Khan SA, Asima B, Hussaini SB, Zakiuddin M, Faisal FA. Morbidity and mortality amongst Indian Hajj pilgrims: A 3-year experience of Indian Hajj medical mission in massgathering medicine. J Infect Public Health. 2018;11(2):165-170. doi:10.1016/j.jiph.2017.06.004.

33. Memish ZA, Khan AA, Ebrahim S. Measles and the 2019 Hajj: the risk of magnifying the global measles surge. J Travel Med. 2019;taz041. doi:10.1093/jtm/taz041.

34. Yanagisawa N, Wada K, Spengler JD, Sanchez-Pina R. Health preparedness plan for dengue detection during the 2020 summer Olympic and Paralympic games in Tokyo. PLOS Negl Trop Dis. 2018;12(9):e0006755. doi:10.1371/journal.pntd.0006755.

35. Venezuela. CDC website. https://wwwnc.cdc.gov/travel/notices/ warning/health-infrastructure-breakdown-venezuela. Accessed July 17, 2019.

36. Korzeniewski K, Juszczak D. Travel-related sexually transmitted infections. Int Marit Health. 2015;66(4):238-246. doi:10.5603/ IMH.2015.0045.

37. Rogstad KE. Sexually transmitted infections and travel. Curr Opin Infect Dis. 2019;32(1):56-62. doi:10.1097/ QCO.0000000000000513.

38. Sundbeck M, Agardh A, Östergren PO. Travel abroad increases sexual health risk-taking among Swedish youth: a population-based study using a case-crossover strategy. Glob Health Action. 2017;10(1):1330511. doi:10.1080/16549716.201 7.1330511 .

39. Sundbeck M, Emmelin A, Mannheimer L, Miörner H, Agardh A. Sexual risk-taking during travel abroad - a cross-sectional survey among youth in Sweden. Travel Med Infect Dis. 2016;14(3):233241. doi:10.1016/j.tmaid.2016.03.014.

40. World Health Organization. Global report on drowning. http:// www.who.int/violence_injury_prevention/global_report_ drowning/final_report_full_web.pdf. Published 2014. Accessed July 17, 2019.

41. Buchan CA, Kotton CN, AST Infectious Diseases Community of Practice. Travel medicine, transplant tourism, and the solid organ transplant recipient - Guidelines from the American Society of Transplantation Infectious Diseases Community of Practice. Clin Transplant. 2019;e13529. doi:10.1111/ctr.13529.

42. Felkai P, Kurimay T. The most vulnerable travelers: patients with mental disorders. World Psychiatry. 2011;10(3):237. doi:10.1002/j.2051-5545.2011.tb00063.x.

43. McIntosh IB, Swanson V, Power KG, et al. Anxiety and health problems related to air travel. J Travel Med. 1998;5(4):198-204. doi:10.1111/j.1708-8305.1998.tb00507.x.

44. World Health Organization (WHO) International Travel and Health. Psychological health. General considerations. 2014. http://www.who.int/ith/other_health_risks/psychological_health/ en/. Accessed July 17, 2019.

45. Palacios-Sánchez L, Botero-Meneses JS, Plazas Pachón R, et al. Stendhal syndrome: a clinical and historical overview. Arq NeuroPsiquiatr. 2018;76(2):120-123. doi:10.1590/0004-282x20170189.

46. Kumar $\mathrm{S}$. An explorative look at Jerusalem syndrome and its validity? Eur Psychiatry. 2017;41:S574. doi:10.1016/j.eurpsy.2017.01.851.

47. Seeman MV. Travel risks for those with serious mental illness. Int J Travel Med Global Health. 2016;4(3):76-81. doi:10.20286/ itmgh-040302. 